\title{
Biodiversitas Capung Subordo Zygoptera Sebagai Bioindikator Kualitas Air Di Aliran Sungai Kawasan Muria Desa Colo Kabupaten Kudus Jawa Tengah
}

\author{
1) Fiki Husnia, 2) Saifullah Hidayat, 3) Siti Mukhlishoh Setyawati \\ 1), 2), 3) UIN Semarang Jawa Tengah Indonesia \\ fikihusnia@gmail.com, hidayatsaifullah@walisongo.ac.id, siti.mukhlishoh@walisongo.ac.id
}

\begin{abstract}
ABSTRAK
Penelitian ini bertujuan untuk mendeskripsikan hasil perhitungan indeks biodiversitas serta nilai FBI (Family Biotic Index) dan menganalisis data keanekaragaman jenis capung subordo Zygoptera sebagai bioindikator kualitas air di aliran sungai kawasan Muria. Jenis penelitian ini termasuk penelitian deskriptif kualitatif. Penelitian dilakukan tanggal 15-25 Agustus 2018 dan tanggal 5-7 Januari 2019 di tiga stasiun yaitu Sungai Kembang, \pm 200 mdpl, Air Terjun Montel, $\pm 600 \mathrm{mdpl}$, dan Sungai Roti, $\pm 800 \mathrm{mdpl}$. Seluruh data capung diambil dengan menggunakan metode jelajah (visual day flying) dan engambilan sampel air dengan menggunakan water sample. Berdasarkan hasil penelitian didapatkan ada 180 individu capung subordo Zygoptera dari 4 spesies dan 4 family yaitu Euphaea variegata (Euphaeidae), Nososticta insignis (Protoneuridae), Vestalis luctuosa (Calopterygidae), dan Copera marginipes (Platycnemididae). Spesies capung yang banyak dijumpai yaitu capung Euphaea variegata yang memiliki indeks kelimpahan paling tinggi. Keanekaragaman jenis bekisar antara 0,7-0,8(rendah), indeks kemerataan jenisnya berkisar antara 0,5-0,6 (cukup merata) dan dominansi jenisnya berkisar antara 0,4-0,5 (sedang) dikarenakan kondisi lingkungan yang kurang stabil sebagai habitat capung. Keanekaragaman jenis capung memiliki keterkaitan sebagai bioindikator kualitas air dan analisis nilai FBI (Family Biotic Index) family Euphaeidae, Protoneuridae, Calopterygidae dan Platycnemididae secara berturut-turut yaitu 3,7; 2,8; 0,1; dan 0,06 yang menunjukkan kualitas air sungai di kawasan Muria desa Colo, Kudus dalam kategori sangat baik dan tidak terpolusi bahan organik. Hal ini membuktikan capung subordo Zygoptera dapat dijadikan sebagai bioindikator kualitas air untuk mengetahui ada tidaknya pencemaran bahan organik di suatu perairan.
\end{abstract}

Kata Kunci: Odonata, Subordo Zygoptera, Kawasan Muria, Indeks Biodiversitas, Nilai FBI (Family Biotic Index)

\section{ABSTRACT}

This study aims to describe the results of the calculation of the biodiversity index and the value of the FBI (Family Biotic Index) and analyze the diversity data of Zygoptera suborder dragonflies as bio-indicators of water quality in the Muria river basin. This type of research is a qualitative descriptive study. The study was conducted on August 15-25, 2018 and January 57, 2019 at three stations, namely Kembang River, \pm 200 masl, Montel Waterfall, \pm 600 masl, and Roti River, \pm 800 masl. All dragonfly data is taken using the cruise method (visual day flying) and water samples are taken using water samples. Based on the results of the study, there were 180 individuals named Zygoptera suborder dragonflies from 4 species and 4 families namely Euphaea variegata (Euphaeidae), Nososticta insignis (Protoneuridae), Vestalis luctuosa (Calopterygidae), and Copera marginipes (Platycnemididae). Dragonflies species that are often found are dragonflies Euphaea variegata which have the highest abundance index. Species diversity ranged from 0.7 to 0.8 (low), evenness index types ranged from 0.5 to 0.6 (fairly evenly distributed) and species dominance ranged from 0.4 to 0.5 (moderate) due to environmental conditions less stable as dragonfly habitat. The diversity of dragonflies has a relationship as a bioindicator of water quality and analysis of the FBI (Family Biotic Index) value of the family Euphaeidae, Protoneuridae, Calopterygidae and Platycnemididae respectively, 3.7; 2.8; 0.1; and 0.06 which shows the quality of river water in the Muria area of Colo village, Kudus in the excellent category and not polluted by organic matter. This proves Zygoptera suborder dragonfly can be used as a bioindicator of water quality to determine whether there is pollution of organic material in a waters. 


\section{PENDAHULUAN}

Indonesia merupakan Negara yang memiliki keanekaragaman hayati yang tinggi, sehingga Indonesia disebut Negara mega biodiversity. Keanekaragaman hayati di Indonesia meliputi 300 spesies bakteri, 38.000 spesies tumbuhan, dan hewan yang mencapai 238.500 jenis, dan yang paling banyak adalah jenis serangga (Sigit et al.,2013). Capung merupakan salah satu jenis keanekaragaman hayati yang dimiliki oleh Indonesia. Ia muncul sejak jaman karbon (360290 juta tahun yang lalu) dan jenis capung yang ada di Indonesia sekitar 700 spesies yakni sekitar 15\% dari 5000 spesies yang ada di dunia (Virgiawan, 2015).

Capung dapat ditemui di beberapa tipe habitat, terutama semua habitat yang dekat lingkungan perairan, karena perairan berkaitan dengan kebutuhan siklus hidupnya (Baskoro ,2018). Kondisi perairan habitat capung sangat berpengaruh terhadap keragaman jenis capung (Rahadi et al. 2013). Capung memiliki manfaat dapat dijadikan sebagai salah satu indikator kualitas air dan mengurangi serangga merugikan seperti nyamuk. Hal ini dikarenakan nimfa capung sangat peka terhadap polutan dan capung merupakan predator bagi jentik-jentik nyamuk (Iskandar, 2015).

Kawasan Gunung Muria merupakan sebuah kawasan yang terletak di wilayah utara Jawa Tengah bagian timur, yang termasuk ke dalam wilayah Kabupaten Kudus di sisi selatan, di sisi barat laut berbatasan dengan Kabupaten Jepara, dan di sisi timur berbatasan dengan Kabupaten Pati. Kawasan ini memiliki beberapa sumber mata air, keberadaan sumber air tersebut merupakan salah satu lingkungan yang sesuai untuk kehidupan mahluk hidup lain seperti hewan dan tumbuhan tertentu agar dapat tumbuh dan berkembangbiak (Khasan, 2011).

Hewan yang banyak dijumpai di lokasi dekat dengan sumber air atau daerah aliran air salah satunya adalah capung (Susanti, 1998). Lingkungan tersebut merupakan habitat yang ideal untuk perkembangbiakan capung (Widjanarko, 2016). Jika habitat tersebut masih dalam lingkup toleransi yang dapat diterima, maka spesies tersebut berpotensi untuk hidup dalam lingkungan atau habitat tersebut (Begon, dkk, 1990, Newman, dkk, 1992).

Kualitas air sangat menentukan kelangsungan hidup biota sungai dan manusia yang memanfaatkan secara langsung air tersebut. Makroinvertebrata seperti capung dapat dijadikan indikator dalam menentukan kualitas air (Tanjung, 2003; Soedradjat, 1999).

\section{METODE PENELITIAN}

Jenis penelitian ini termasuk penelitian deskriptif kualitatif (Sukmadinata, 2011). Deskriptif kualitatif dalam penelitian ini digunakan untuk mengembangkan teori yang dibangun melalui data yang diperoleh di lapangan (Sugiyono, 2003). Penelitian ini dilaksanakan pada tanggal 15 25 Agustus 2018 dan tanggal 5-7 Januari 2019 di tiga stasiun yaitu Sungai Kembang(200 mdpl), Air Terjun Montel(600 mdpl) dan Sungai Roti (800 mdpl) dengan pengambilan sampling wilayah secara purposive sampling. Sedangkan tempat untuk menguji kualitas airnya (BOD dan COD) dilakukan di UNDIP (Laboratorium Teknik Lingkungan) dan uji logam $(\mathrm{Fe}, \mathrm{Pb}$, dan $\mathrm{Cl}$ ) dilakukan di UNNES (Laboratorium Teknik Lingkungan). 


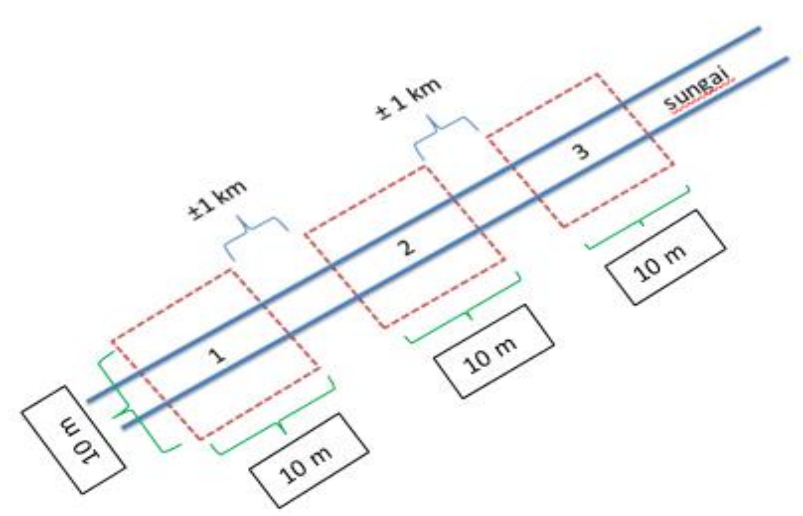

Gambar 3.1. Denah lokasi sampling (Tim Riset Capung Muria, 2018)

Ket : $\quad$ - Kotak merah = lokasi sampling $(1,2,3)$

- Sungai Kembang(1), Air Terjun Montel(2) dan Sungai Roti(3)

- Garis biru = aliran sungai

Seluruh data capung diambil dengan menggunakan metode jelajah (visual day flying). Pengambilan data dan sampel di lapangan dilakukan pada pagi hari mulai pukul 08.00 sampai 11.00 WIB (Siregar, 2016). Pengambilan sampel air pada masing-masing stasiun dilakukan dengan menggunakan water sample pada kedalaman terdekat dengan dasar perairan sungai (Fachrul, 2007).

Identifikasi dilakukan dengan teknik identifikasi Simpson (2006) yang bisa dilakukan dengan 5 kegiatan yaitu menggunakan kunci identifikasi, deskripsi berdasarkan literatur, spesimen pembanding, foto atau gambar serta institusi yang berkompeten. Pengukuran parameter lingkungan (suhu, salinitas air, $\mathrm{pH}$, intensitas cahaya, dan kelembapan) yaitu $\mathrm{pH}$ meter, thermometer, salinometer, roll meter, luxmeter, dan hygrometer. Sedangakan untuk megukur kualitas air seperti kadar BOD dengan metode Winkler-Alkali iodida azida, kadar COD dengan peralatan khusus reflux, serta logam dengan menggunakan alat Atomic Adsorbtion Spectophotometer (AAS).

\section{HASIL DAN PEMBAHASAN}

Tabel 4.1. Jumlah Spesies Capung Subordo Zygoptera Di Kawasan Aliran Sungai Gunung Muria Desa Colo Kudus Jawa Tengah

\begin{tabular}{|c|c|c|c|c|c|c|c|c|}
\hline \multirow{2}{*}{ No. } & \multirow{2}{*}{ Penelitian Ke- } & \multicolumn{2}{|c|}{ Stasiun 1} & \multicolumn{2}{|c|}{ Stasiun 2} & \multicolumn{2}{|c|}{ Stasiun 3} & \multirow{2}{*}{$\begin{array}{l}\text { Jumlah Total } \\
\text { Tiap Spesies }\end{array}$} \\
\hline & & I & II & I & II & I & II & \\
\hline \multirow{2}{*}{1.} & Euphaea variegata (Jantan) & 19 & 5 & 28 & 23 & 25 & 6 & 106 \\
\hline & Euphaea variegata (Betina) & - & 1 & 1 & 2 & 1 & - & 5 \\
\hline \multirow{2}{*}{2.} & Nososticta insignis (Jantan) & 3 & 9 & 18 & 4 & 20 & 6 & 60 \\
\hline & Nososticta insignis (Betina) & 1 & - & - & 1 & - & 1 & 3 \\
\hline 3. & Vestalis luctuosa (Jantan) & - & 1 & - & 2 & - & 1 & 4 \\
\hline 4. & Copera marginipes (Betina) & - & - & 1 & 1 & - & - & 2 \\
\hline \multicolumn{2}{|c|}{ Jumlah Total Seluruh Spesies (ekor) } & \multicolumn{2}{|c|}{39} & \multicolumn{2}{|c|}{81} & \multicolumn{2}{|c|}{60} & 180 \\
\hline
\end{tabular}


Tabel 4.2. Klasifikasi Capung Subordo Zygoptera (Baskoro,dkk., 2018)

\begin{tabular}{|c|c|c|c|c|c|c|c|}
\hline Kerajaan & Filum & Kelas & Ordo & Subordo & Famili & Genus & Spesies \\
\hline \multirow{4}{*}{ Animalia } & \multirow{4}{*}{ Arthropoda } & \multirow{4}{*}{ Insekta } & \multirow{4}{*}{ Odonata } & \multirow{4}{*}{ Zygoptera } & Euphaeidae & Euphaea & $\begin{array}{l}\text { Euphaea } \\
\text { variegata }\end{array}$ \\
\hline & & & & & Protoneuridae & Nososticta & $\begin{array}{l}\text { Nososticta } \\
\text { insignis }\end{array}$ \\
\hline & & & & & Platycnemididae & Copera & $\begin{array}{l}\text { Copera } \\
\text { marginipes }\end{array}$ \\
\hline & & & & & Calopterygidae & Vestalis & $\begin{array}{l}\text { Vestalis } \\
\text { luctuosa }\end{array}$ \\
\hline
\end{tabular}

Tabel 4.3. Parameter Fisika pada Tiga Stasiun Penelitian di Sekitar Aliran Sungai Gunung Muria Desa Colo Kudus Jawa Tengah.

\begin{tabular}{|c|l|c|c|c|}
\hline NO. & \multicolumn{1}{|c|}{ Pengukuran } & Stasiun I & Stasiun II & Stasiun III \\
\hline 1. & Suhu Udara $\left({ }^{0} \mathrm{C}\right)$ & 24,95 & 24,15 & 26,45 \\
\hline 2. & Kelembapan $\left(\%{ }^{\mathrm{rh}}\right)$ & 66,03 & 66,88 & 60,63 \\
\hline 3. & Salinitas Air $(\mathrm{ppt})$ & 0 & 0 & 0 \\
\hline 4. & pH Air & 7,05 & 7,4 & 1215,7 \\
\hline 5. & Intensitas Cahaya $(\mathrm{Cd})$ & 701,06 & 544,9 & 23 \\
\hline 6. & Suhu Air $\left({ }^{0} \mathrm{C}\right)$ & 23 & 23 & \\
\hline
\end{tabular}

Pengukuran parameter fisik lingkungan pada saat penelitian berlangsung menunjukkan bahwa setiap stasiun memiliki kondisi fisik yang tidak jauh berbeda. Data yang diperoleh menunjukkan terdapat hubungan antara faktor fisik lingkungan dengan keberadaan capung pada masing-masing stasiun penelitian. Perbedaan yang terlihat yaitu intensitas cahaya pada ketiga stasiun tersebut. Hal ini dikarenakan adanya perbedaan tutupan tumbuhan kanopi (Lampiran 6. Vegetasi) yang ada pada masing-masing stasiun. Terdapat satu spesies capung yang paling mudah dijumpai pada ketiga stasiun tersebut yaitu Euphaea variegata, jenis ini sangat umum dijumpai pada kawasan Muria. Euphaea variegata mampu hidup pada berbagai tipe habitat seperti sungai dekat dengan hutan, sungai dalam hutan dan hutan.

Tabel 4.4. Parameter Kimia pada Tiga Stasiun Penelitian di Sekitar Aliran Sungai Gunung Muria Desa Colo Kudus Jawa Tengah

\begin{tabular}{|l|c|c|c|c|c|c|}
\hline \multicolumn{1}{|c|}{ Lokasi } & Satuan & COD & B0D & Cl & Pb & Fe \\
\hline Stasiun 1 & $\mathrm{mg} / \mathrm{L}$ & 3,9 & 1,2 & 249,30 & 0 & 0 \\
\hline Stasiun 2 & $\mathrm{mg} / \mathrm{L}$ & 16,8 & 5,2 & 237,20 & 0,138 & 0 \\
\hline Stasiun 3 & $\mathrm{mg} / \mathrm{L}$ & 13,5 & 4,2 & 307,11 & 0 & 0 \\
\hline
\end{tabular}

Hasil uji sampel air di stasiun I memiliki nilai COD sebesar 3,9 mg/L, nilai BOD sebesar 1,2 mg/L, kandungan unsur $\mathrm{Cl}$ 249,30 mg/L, kandungan logam berat $\mathrm{Pb} 0 \mathrm{mg} / \mathrm{L}$, dan kandungan logam Fe 0 mg/L yang menunjukkan bahwa di stasiun I kualitas airnya masih bagus sebagai air baku untuk air minum.

Hasil uji sampel air di stasiun II memiliki nilai COD sebesar 16,8 mg/L, nilai BOD sebesar 5,2 mg/L, kandungan unsur $\mathrm{Cl}$ 237,20 mg/L dan kandungan logam Fe $0 \mathrm{mg} / \mathrm{L}$ yang menunjukkan kualitas airnya baik untuk sarana/prasarana rekreasi air dan budidaya perairan. Tetapi air di stasiun II terdapat kandungan logam berat $\mathrm{Pb} 0,138 \mathrm{mg} / \mathrm{L}$ sudah melampaui ambang batas maksimum yang diperbolehkan.

Hasil uji sampel air di stasiun III memiliki nilai COD sebesar 13,5 mg/L, nilai BOD sebesar 4,2 mg/L, kandungan unsur $\mathrm{Cl}$ 307,11 mg/L, kandungan logam $\mathrm{Pb} 0 \mathrm{mg} / \mathrm{L}$, dan 
kandungan logam $\mathrm{Fe} 0 \mathrm{mg} / \mathrm{L}$ yang menunjukkan kualitas airnya masih baik untuk budidaya perairan, misalnya budidaya ikan air tawar.

Capung Zygoptera memiliki ukuran tubuh lebih kecil daripada capung Anisoptera, terutama pada bagian abdomen. Capung Zygoptera umumnya memiliki tubuh berbentuk silindris dan perawakan tubuh ramping menyerupai jarum, bentuk sayap depan dan belakang sama serta kedua mata majemuknya terpisah atau tidak menempel. Capung Zygoptera memiliki kepala berbentuk horizontal. Pada beberapa jenis terutama individu jantan warna tubuh dan sayapnya memiliki warna yang cenderung menyolok, sehingga menarik untuk diperhatikan. Apabila diamati sayap capung Zygoptera cenderung menutup ketika hinggap/ istirahat, kecuali pada Famili Lestidae. Capung ini umumnya kurang kuat terbang, sehingga jarang terlihat melayanglayang di suatu tempat dan gerakan terbangnya lambat, diperkirakan berkecepatan $10 \mathrm{~km} / \mathrm{jam}$ (Hanum, 2013), sehingga mudah ditangkap dan diamati perilakunya.

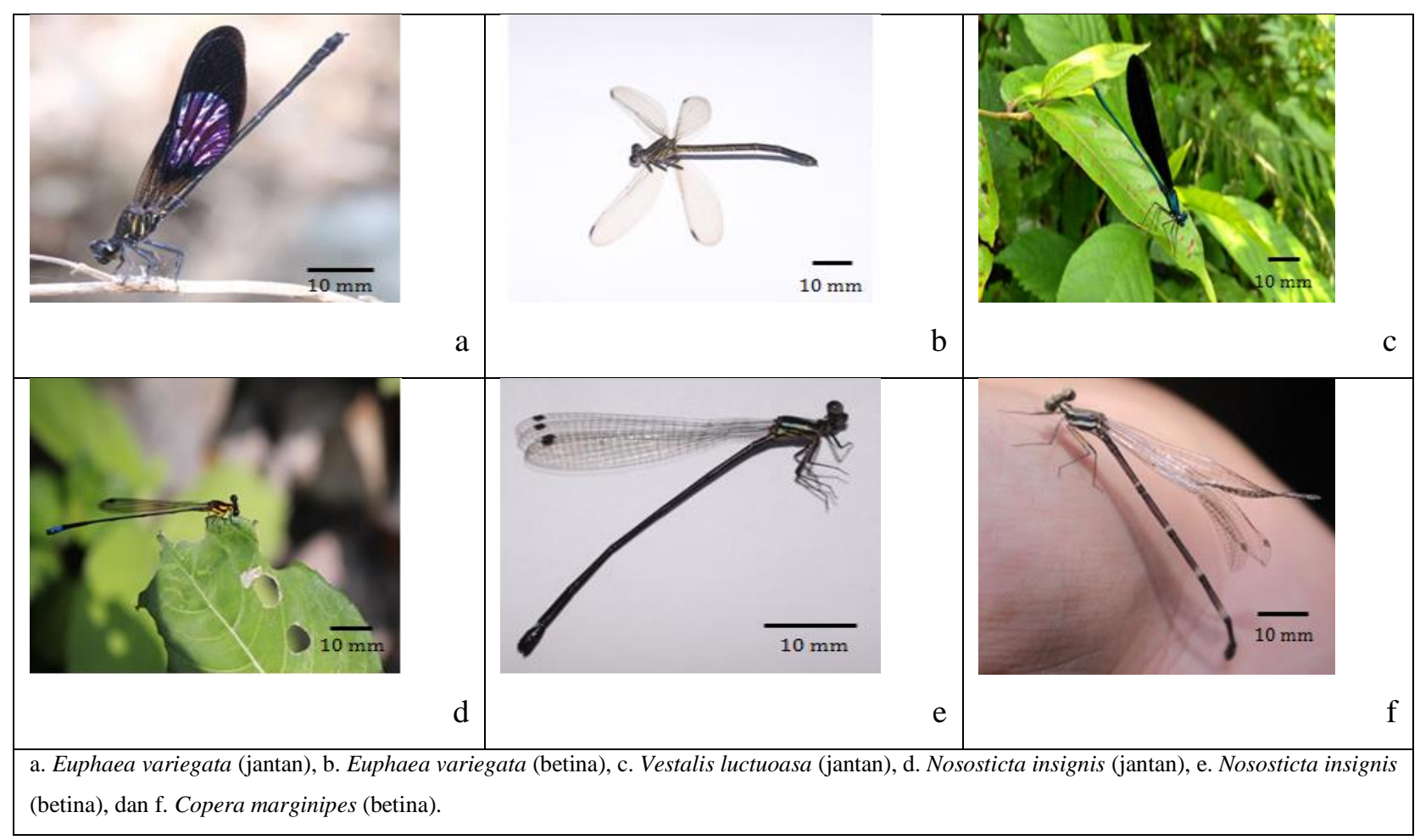

Tabel 4.5. Indeks Kelimpahan Relatif

\begin{tabular}{|c|c|c|c|c|}
\hline \multirow{2}{*}{ No. } & \multirow{2}{*}{ Nama spesies } & \multicolumn{3}{|c|}{ Kelimpahan Relatif (KR) } \\
\cline { 3 - 5 } & & Stasiun I & Stasiun II & Stasiun III \\
\hline 1. & Euphaea variegata & 0,641026 & 0,666667 & 0,533333 \\
\hline 2. & Nososticta insignis & 0,333333 & 0,283951 & 0,45 \\
\hline 3. & Vestalis luctuosa & 0,025641 & 0,024691 & 0,016667 \\
\hline 4. & Copera marginipes & - & 0,024691 & - \\
\hline
\end{tabular}

Tabel 4.6. Indeks Keanekaragaman Jenis

\begin{tabular}{|c|c|c|c|}
\hline No. & Lokasi & Indeks keanekaragaman jenis $\left(\mathbf{H}^{\prime} \mathbf{)}\right.$ & Kategori \\
\hline 1. & Stasiun I & 0,745197 & Rendah \\
\hline 2. & Stasiun II & 0,810571 & Rendah \\
\hline 3. & Stasiun III & 0,762825 & Rendah \\
\hline
\end{tabular}


Tabel 4.7. Indeks Kemerataan

\begin{tabular}{|c|c|c|c|}
\hline No. & Lokasi & Indeks kemerataan (E) & Kategori \\
\hline 1. & Stasiun I & 0,678307166 & Cukup merata \\
\hline 2. & Stasiun II & 0,584703704 & Cukup merata \\
\hline 3. & Stasiun III & 0,694353685 & Cukup merata \\
\hline
\end{tabular}

Tabel 4.8. Indeks Dominansi

\begin{tabular}{|c|c|c|c|}
\hline No. & Lokasi & Indeks dominansi (Di) & Kategori \\
\hline 1. & Stasiun I & 0,510121457 & Dominansi sedang \\
\hline 2. & Stasiun II & 0,52037037 & Dominansi sedang \\
\hline 3. & Stasiun III & 0,478531073 & Dominansi sedang \\
\hline
\end{tabular}

Tabel 4.9. Nilai FBI (Family Biotic Index)

\begin{tabular}{|c|c|c|c|c|c|}
\hline No. & Family & $\begin{array}{c}\text { Jumlah } \\
\text { Individu (xi) }\end{array}$ & $\begin{array}{c}\text { Nilai } \\
\text { Toleransi (ti) }\end{array}$ & xi.ti/N & Nilai FBI \\
\hline 1. & Euphaeidae & 111 & 6 & $666 / 180$ & 3,7 \\
\hline 2. & Protoneuridae & 63 & 8 & $504 / 180$ & 2,8 \\
\hline 3. & Calopterygidae & 4 & 5 & $20 / 180$ & 0,1 \\
\hline 4. & Platycnemididae & 2 & 6 & $12 / 180$ & 0,06 \\
\hline \multicolumn{2}{|c|}{ Total (ekor) } & 180 & & & \\
\hline
\end{tabular}

\begin{tabular}{|l|l|l|}
\hline \multicolumn{1}{|c|}{ Family Biotic Index } & \multicolumn{1}{|c|}{ Kualitas Air } & \multicolumn{1}{c|}{ Tingkat Pencemaran } \\
\hline $0,0-3,75$ & Sangat Baik & Tidak terpolusi bahan organik \\
\hline $3,76-4,25$ & Baik sekali & Sedikit terpolusi bahan organik \\
\hline $4,26-5,00$ & Baik & Terpolusi beberapa bahan organik \\
\hline $5,01-5,75$ & Cukup & Terpolusi agak banyak \\
\hline $5,76-6,50$ & Agak buruk & Terpolusi banyak \\
\hline $6,51-7,25$ & Buruk & Terpolusi sangat banyak \\
\hline $7,26-10,00$ & Buruk sekali & Terpolusi berat bahan organik \\
\hline
\end{tabular}

Perhitungan nilai FBI (Family Biotic Index) dari keempat family capung tersebut menunjukkan nilai FBI berkisar antara 0,06-3,7 dimana angka ini termasuk dalam kategori kualitas air sangat baik dengan tingkat pencemaran rendah/tidak terpolusi oleh bahan organik. Hal ini juga didukung oleh nilai BOD dan COD nya tidak melampaui ambang batas maksimum yang juga mempengaruhi kondisi kimia perairan habitat capung sebagai syarat hidup organisme dan membuktikan capung subordo Zygoptera mempunyai potensi sebagai bioindikator kualitas air apakah air tersebut tercemar bahan organik atau tidak. Tetapi, ada salah satu stasiun yang memiliki cemaran logam berat (bukan bahan organik) yaitu di stasiun kedua tepatnya di kawasan wisata Air Terjun Montel, logam tersebut adalah timbal $(\mathrm{Pb})$. 


\section{SIMPULAN}

1. Keanekaragaman capung subordo Zygoptera yang ditemukan, terdapat 4 jenis capung dari 4 famili yang berbeda yaitu Euphaea variegata (family Euphaeidae), Vestalis luctuosa (family Calopterygidae), Nososticta insignis (family Protoneuridae), dan Copera marginipes (Platycnemididae). Berikut adalah hasil perhitungan indeks kelimpahan relatif di ketiga stasiun penelitian yaitu Euphaea variegata berkisar antara 0,5-0,6 \%, Nososticta insignis berkisar antara 0,2-0,4\%, Vestalis luctuosa berkisar antara 0,010,02\% dan Copera marginipes 0,02\%. Indeks keanekaragaman jenisnya yaitu Stasiun I memiliki indeks keanekaragaman 0,745197, Stasiun II : 0,810571 dan Stasiun III : 0,762825. Ketiganya memiliki tingkat keanekaragaman jenis yang rendah. Indeks kemerataan jenisnya di ketiga stasiun yaitu Stasiun I memiliki nilai indeks kemerataan 0,678307166, Stasiun II: 0,584703704 dan Stasiun III : 0,694353685. Ketiganya memiliki nilai indeks kemerataan dalam kategori cukup merata. Dominansi di ketiga stasiun yaitu Stasiun I memiliki nilai indeks dominansi 0,510121457, Stasiun II : 0,52037037 dan Stasiun III : 0,478531073. Ketiganya memiliki nilai indeks dominansi sedang. Sedangkan nilai FBI (Family Biotic Index) dari keempat family capung secara berturut-turut yaitu family Euphaeidae 3,7 ; family Protoneuridae 2,8 ; family Calopterygidae 0,1; dan family Platycnemididae 0,06.

2. Capung subordo Zygoptera dapat dijadikan sebagai bioindikator kualitas air di aliran sungai kawasan Muria berdasarkan perhitungan nilai FBI (Family Biotic Index) dari keempat family dengan nilai FBI berkisar antar 0,06-3,7 yang menunjukkan kualitas air yang baik dan tidak terpolusi oleh bahan organik.

\section{DAFTAR PUSTAKA}

Baskoro, K., Irawan, F., Kamaludin, N. 2018. Odonata Semarang Raya Atlas Biodiverstas Di Kawasan Semarang. Semarang: Departemen Biologi Fakultas Sains Dan Matematika Universitas Diponegoro.

Begon, M; Harper, J.L; dan Toensend, C.R.1990. Ecology. Oxford: Blackwell Science Ltd

Candra Virgiawan dkk,. 2015. Studi Keanekaragaman Capung (Odonata) Sebagai Bioindikator Kualitas Air Sungai Brantas Batu-Malang Dan Sumber Belajar Biologi. JURNAL PENDIDIKAN BIOLOGI INDONESIA.1(2).188-196

Fachrul, Melati Ferianita. 2007. Metode Sampling Bioekologi. Jakarta: PT Bumi Aksara

Hanum S.O, Salmah S, Dahelmi. 2013. Jenis-jenis Capung (Odonata) di Kawasan Taman Satwa Kandi Kota Sawahlunto, Sumatera Barat. J Bio UA 2: 71-76

Iskandar. 2015. Metodelogi Penelitian Pendidikan dan Sosial. Jakarta: Referensi.

Khasan, Mohammad. 2015. Perilaku Teritorial pada Penggunaan Air di Desa Colo Kabupaten Kudus. Tesis. Semarang: Universitas Katolik Soegijapranata

Rahadi WS, Feriwibisono B, Nugrahani MP, et al. 2013. Naga Terbang Wendit, Keanekaragaman Capung Perairan Wendit, Malang, Jawa Timur. Malang: Indonesia Dragonfly Society 
Sigit, W., Feriwibisono, B., Nugrahani, M. P., Putri, B. dan Makitan, T. 2013. Naga Terbang Wendit : Keanekaragaman Capung Perairan Wendit, Malang. Malang: Indonesia Dragonfly Society

Siregar, A. Z., 2016. Keanekaragaman Dan Konservasi Status Capung Di Kampus Hijau Universitas Sumatera Utara Universitas, Medan-Indonesia. Pertanian Tropik, 3(1)

Sugiyono. 2003. Metode Penelitian Kuantitatif Kualitatif dan R\&D. Bandung: CV. Alfabeta

Sukmadinata, Nana Syaodih. 2011.Metode Penelitian Pendidikan.Bandung: PT Remana Rosdakarya

Susanti, Shanti. 1998. Mengenal capung. LIPI-seri panduan lapangan. Bogor :Puslitbang Biologi. LIPI

Tanjung, S.D. 2003. Ilmu Lingkungan.Laboratorium Ekologi, Fakultas Biologi, Universitas Gadjah Mada. Yogjakarta: Gadjah Mada University press

Widjanarko, M., \& Wismar'ein, D.,2016. Identifikasi Sosial Potensi Ekowisata Berbasis Peran Masyarakat Lokal. Jurnal Psikologi, 